\title{
MORFOLOGIA DE FRUTOS DE GOIABEIRA ${ }^{1}$
}

\author{
FABÍOLA VITTI MÔRO²; WILLIAM NATALE³; CARLOS FERREIRA DAMIÃO FILHO², RENATO DE MELLO PRADO
}

RESUMO-A eficiência na absorção de nutrientes pelos frutos pode sofrer interferências em função da estrutura morfológica presente. Assim, frente à importância do conhecimento da morfologia dos frutos para um manejo mais adequado dos pomares em termos de adubação foliar, ou de tratamentos pós-colheita para ampliar a vida útil dos mesmos, desenvolveu-se o presente estudo, cujo objetivo foi descrever a morfologia do pericarpo dos frutos de goiabeira. Para isto, amostras do pericarpo de goiabas (cv. Paluma) foram observadas ao microscópio ótico e eletrônico de varredura. Algumas das características observadas, como a presença de cutícula espessa, cêra epicuticular, três camadas subepidérmicas de células compactas e grande quantidade de esclereídeos, bem como a presença esporádica e dispersa de estômatos, podem constituir-se em barreiras para a absorção e movimentação de nutrientes e substâncias aplicadas aos frutos de goiabeira.

Termos para indexação: Psidium guajava, fruta, pericarpo, microscópio eletrônico de varredura.

\section{MORPHOLOGY OF GUAVA FRUITS}

ABSTRACT-The efficience of nutrients absortion by the fruits can be influenced by the morphological structures of the pericarp. The present research aimed to describe the pericarp morphology of guava fruits, considering the importance of this information to proceed an adequate management in leaf adubation or post harvest treatments to increase fruit's lifetime in guava orchards. The guava fruits (cv. Paluma) pericarp samples were evaluated under optical and scanning electron microscopy. Some of the characteristics observed were the thick cuticle, epicuticular wax, three subepidermical layers of compact cells and a high amount of esclerídeos. These characteristics can be considered barriers for absortion and movement of substances in guava fruits.

Index Terms: Psidium guajava, fruit, pericarp, scanning electron microscopy.

\section{INTRODUÇÃO}

A aplicação foliar de produtos (hormônios, defensivos, fertilizantes) tem sido realizada com relativo sucesso, dependendo especialmente de fatores inerentes às plantas.

Aplicações foliares de nutrientes em plantas frutíferas atingem também os frutos, quando estes estão presentes. Pouco se sabe, porém, sobre os efeitos dessas aplicações e o destino dos elementos que neles são pulverizados, por desconhecer-se a estrutura dos frutos.

Não raro se encontram na literatura relatos da aplicação de elementos químicos em frutos colhidos, a fim de prolongar sua vida útil, cujos resultados podem ser positivos, negativos ou inócuos, de forma que os benefícios desta técnica são contraditórios. Há resultados favoráveis na qualidade pós-colheita em algumas fruteiras, como em morango (Cheour et al., 1991), maçã (Lurie \& Klein, 1992), maracujá (Silva \& Vietes, 2000) e sem efeito significativo, em jabuticabas (Mota et al., 1997) e goiaba cv. Kumagai (Carvalho et al., 1998). Em mangueira, aplicações (até 4 vezes) durante o desenvolvimento dos frutos também não apresentaram efeito benéfico na qualidade da fruta, visto que não houve incremento de cálcio na polpa (Rabelo et al., 1996; Silva \& Menezes, 2000). Em olerícolas, como o tomateiro, Castellane (1988) recomenda a aplicação de cálcio diretamente nos frutos, a fim de prevenir a anomalia conhecida como podridão apical. Apesar de o cálcio ser sabidamente um elemento imóvel no floema, esse tipo de tratamento é eficiente devido às características da planta e à pulverização localizada.

Danieli et al. (2002) não obtiveram efeito benéfico na aplicação de $\mathrm{CaCl} 2$ no retardamento da colheita de caqui e, quando combinado ao AG3, o cloreto de cálcio reduziu os efeitos benéficos do hormônio após a colheita. Objetivando buscar um controle mais adequado de doenças, Tozello \& Ribeiro (1998) aplicaram $\mathrm{CaCl}_{2}$ no tratamento pós-colheita de goiabas, não obtendo efeito favorável.

$\mathrm{O}$ estudo da morfologia dos frutos poderia responder a algumas questões, como, por exemplo, se a presença de certas estruturas dificultaria a absorção e movimento de substâncias.

No caso da goiabeira, planta tipicamente tropical, Môro et al. (1999) descreveram nas folhas a presença de uma hipoderme com célu- las de paredes espessadas, grande quantidade de fibras em torno dos feixes vasculares, células contendo cristais de sílica (drusas) e, também, que as folhas são hipoestomáticas, isto é, os estômatos estão presentes apenas na superfície inferior das folhas. Todos esses aspectos são, provavelmente, adaptações dessa Myrtacea à economia de água, mas que, ao mesmo tempo, poderiam dificultar a penetração de elementos químicos.

Natale et al. (1999), trabalhando com aplicação foliar de fósforo radioativo $\left({ }^{32} \mathrm{P}\right)$, relataram a baixa absorção do elemento pelas folhas de goiabeira, provavelmente, descritas por Môro et al. (1999), às quais dificultam a absorção dos nutrientes.

Tendo em vista o exposto e considerando a importância do conhecimento da morfologia dos frutos para um manejo mais adequado dos pomares, em termos de adubação foliar, ou de tratamentos póscolheita para ampliar a vida útil dos frutos, desenvolveu-se a presente pesquisa, cujo objetivo foi descrever a morfologia dos frutos de goiabeira.

\section{MATERIALE MÉTODOS}

Foram utilizados frutos de goiabeira (Psidium guajava L.) da cultivar Paluma. Para a observação ao microscópio ótico, pequenas porções do pericarpo do fruto foram colocadas em frascos de vidro contendo solução de FAA (formalina-aceto-álcool: $90 \mathrm{ml}$ de etanol 50\%, $5 \mathrm{ml}$ de ácido acético glacial e $5 \mathrm{ml}$ de formaldeído a $37 \%$ ), por 48 horas. Após este período, as amostras foram cortadas transversalmente, com o auxílio de lâmina de barbear, montadas em lâminas histológicas contendo safranina aquosa a $1 \%$, cobertas com lamínula e fotografadas em microscópio ótico.

Para observação ao microscópio eletrônico de varredura, amostras do pericarpo dos frutos foram fixadas em glutaraldeído a $3 \%$, em solução tampão de fosfato de potássio a $0,05 \mathrm{M} \mathrm{e} \mathrm{pH} \mathrm{7,4} \mathrm{por} 48$ horas, a $10^{\circ} \mathrm{C}$. A seguir, o material foi pós-fixado em tetróxido de ósmio a $1 \%$ na mesma solução tampão e mantido em refrigerador por 24 horas. As amostras foram então desidratadas em álcool etílico, na série gradual : $30 ; 50$; $70 ; 80 ; 95$ e $100 \%$

\footnotetext{
(Trabalho 092/2002). Recebido: 24/06/02; Aceito para publicação: 13/03/03.

2 Departamento de Biologia, UNESP/FCAV - Faculdade de Ciências Agrárias e Veterinárias - Câmpus de Jaboticabal. Via de Acesso Prof. Paulo Donato Castellane, s/ n - 14884-900 - Jaboticabal - SP.
}

${ }^{3}$ Departamento de Solos e Adubos, UNESP/FCAV. 
Submeteram-se as amostras à secagem em secador de ponto crítico e, posteriormente, as mesmas foram fixadas sobre suportes metálicos, recobertas com uma camada de $35 \mathrm{~nm}$ de ouro-paládio e observadas ao microscópio eletrônico de varredura.

\section{RESULTADOS E DISCUSSÃO}

Nos cortes transversais, observados em microscópio ótico, verificou-se a presença de cutícula espessa (Figura 1A). O grau de espessamento da cutícula pode ser usado como caráter taxonômico (Rosso, 1966). Entretanto, Withner et al. (1974) relataram que o padrão de espessamento da cutícula é determinado pela exposição ao sol, sendo que a parte vegetal mais exposta tende a exibir uma cutícula mais espessa.

Observou-se, abaixo da epiderme, três camadas subepidérmicas de células compactas, arredondadas, poligonais e de diferentes tamanhos (Figura 1B). Segundo Kurzweil et al. (1995), células epidérmicas maiores estão relacionadas à função de reserva de água.

As camadas tissulares subseqüentes são constituídas de células parenquimáticas poliédricas, entremeadas por esclereídeos agrupados (células pétreas). O tecido vascular não é evidente nesse tipo de corte. Observou-se, ainda, a presença de grande quantidade de estruturas secretoras internas (cavidades lisígenas) logo abaixo da epiderme (Figura 1C)
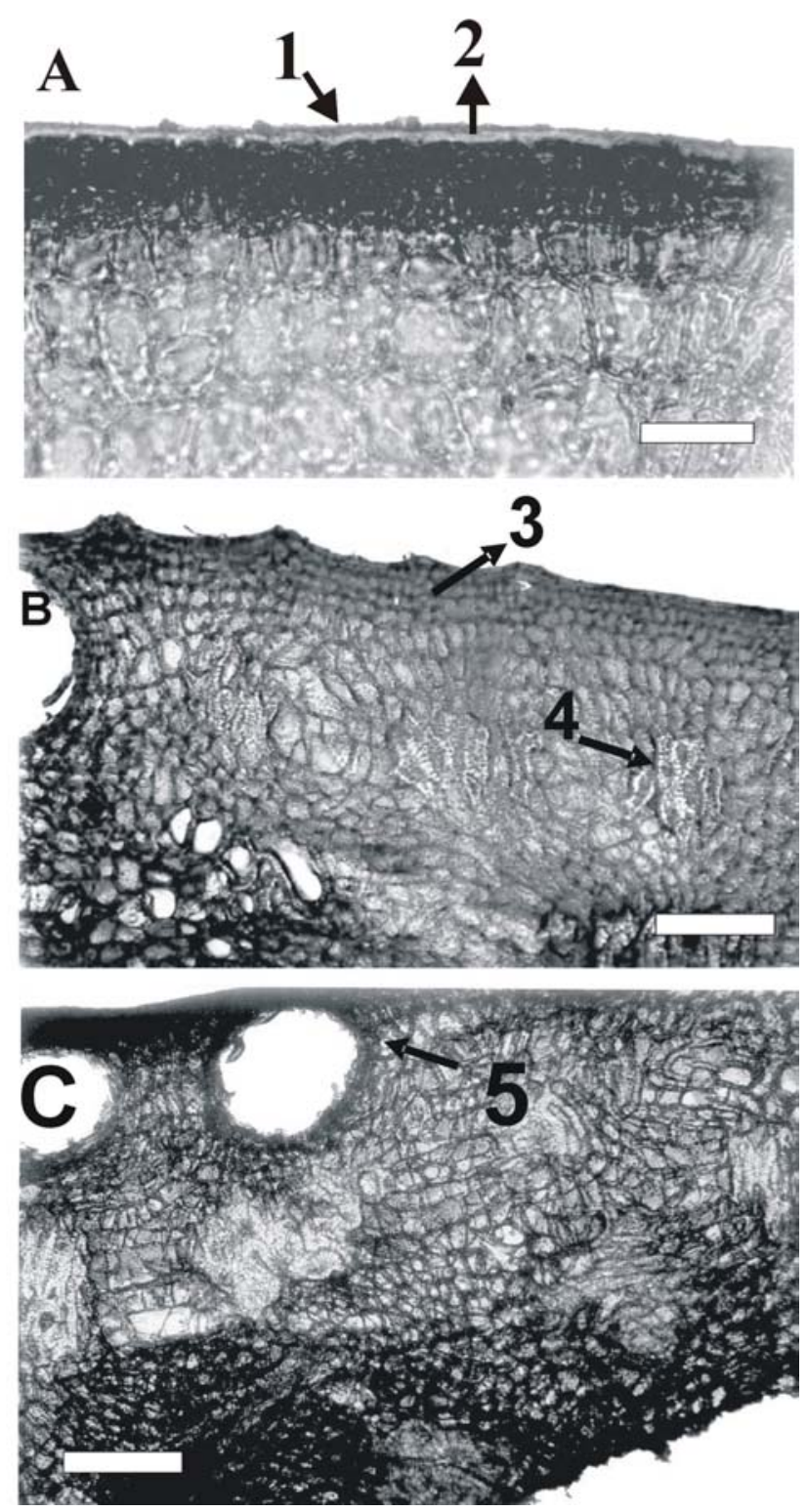

FIGURA 1- A), B) e C) Cortes transversais do pericarpo do fruto de Pisidium guajava (1.cutícula; 2 . células epidérmicas; 3 . camadas subepidérmicas; 4. esclereídeos; 5 . cavidade lisígena) (Figura A barra $=30 \mu \mathrm{m}$; Figura B e C barra $=100 \mu \mathrm{m}$ ).
Pela Figura 2, observa-se, na superfície externa do pericarpo, ao microscópio eletrônico de varredura, a presença de manchas claras que, em vista frontal, correspondem à cera epicuticular que, em corte transversal, estariam relacionadas às saliências irregulares da cutícula (Figura 1A). Karcz (1996) também observarou a presença de cera epicuticular nas células da epiderme de frutos da Valeriana officinarum. Ainda na Figura 2, verificaram-se estômatos paracíticos salientes, com células-guarda reniformes semelhantes àqueles observados na face inferior de folhas de goiabeira cv. Paluma por Môro et al. (1999). Porém, a presença de estômatos nos frutos é considerada esporádica e dispersa quando comparadas às folhas. Resultados semelhantes, quanto à presença dispersa de estômatos em frutos, foram relatados em Ribes rubrum (Blanke, 1993) e em abacate (Blanke \& Lovatt, 1993). Porém, Landrigan et al. (1994) verificaram a presença de grande quantidade de estômatos em frutos de Nephelium lappaceum (Rambutam).

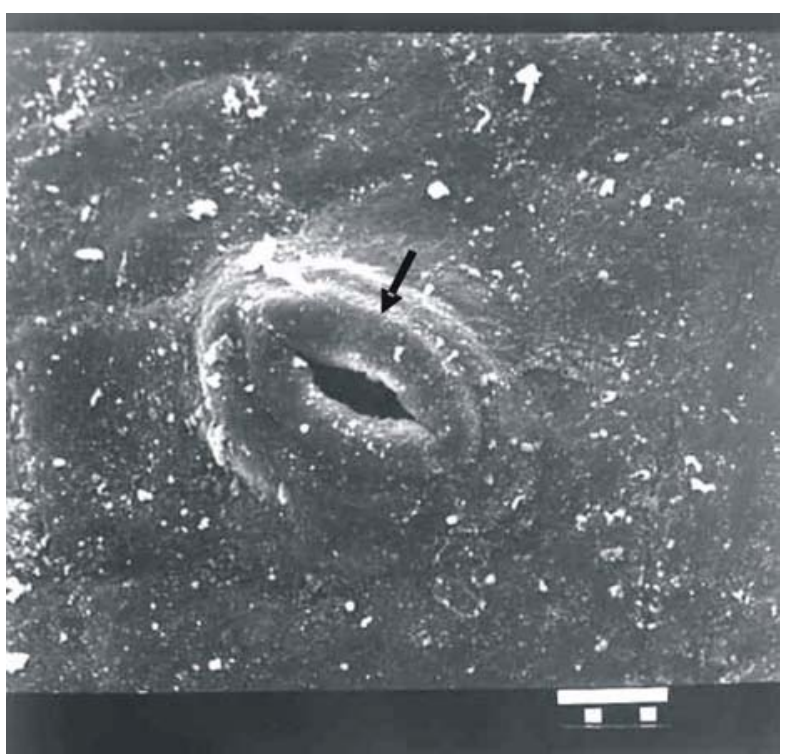

FIGURA 2- Estômato, presente na superfície externa do pericarpo do fruto de Psidium guajava $(\rightarrow$ ) (barra=10 $\rightarrow \mathrm{m})$.

Sabe-se que os estômatos apresentam permeabilidade relativa à passagem de nutrientes. Assim, informações obtidas neste tipo de estudo permitem inferir que os parcos resultados positivos verificados com a aplicação de nutrientes, a exemplo do $\mathrm{Ca}$, na qualidade pós-colheita de frutos, podem decorrer da ausência ou presença esporádica de estruturas permeáveis nos frutos.

Cabe ressaltar que existem situações em que o nutriente aplicado ao fruto pode até aumentar o teor total do elemento no tecido, embora sem reflexos na qualidade. Este fato é explicado por Malta (2000), tendo em vista que o teor total do elemento, obtido pela digestão nitroperclórica e utilizado na análise química de rotina, parece não ser melhor indicativo do status nutricional, pois, através dessa análise, não se pode ter certeza da localização subcelular do nutriente. Assim, o elemento pode estar tanto adsorvido à cutícula do fruto como fora dos sítios de maior atividade metabólica da célula. Neste sentido, a análise química padrão, pelo teor total, deve ser utilizada com restrição, pois determinações mais específicas, como a análise do nutriente em nível subcelular (parede celular, cloroplasto e o solúvel), utilizando metodologia conhecida (Favero, 1992), podem auxiliar e melhorar as interpretações do verdadeiro estado nutricional dos frutos e definir a real eficiência de uso da tecnologia de aplicação de nutrientes ou substâncias via frutos.

Por outro lado, os resultados positivos na qualidade pós-colheita com a aplicação de nutrientes em determinados frutos, como morango (Cheour et al., 1991), maçã (Lurie \& Klein, 1992) e maracujá (Silva \& Vieites, 2000 ), podem decorrer do tipo de morfologia presente nestes frutos, que facilitariam a penetração e metabolização de nutrientes.

Assim, o conhecimento prévio da morfologia dos frutos, determinando-se as estruturas que os formam, pode ser utilizado para fundamentar estudos de viabilidade de aplicação de nutrientes e outras subs- 
tâncias em frutos, visando à qualidade pós-colheita, visto que a expressão dos efeitos benéficos das aplicações na melhoria da qualidade da fruta é proporcional à quantidade absorvida, metabolizada e acumulada nos tecidos vegetais.

Observou-se, ainda, que os esclereídeos, na face interna do pericarpo, possuem parede secundária bastante espessa (Figura 3A). As cavidades lisígenas, ao microscópio eletrônico de varredura, mostram-se contornadas por várias camadas de células (indicadas na seta) (Figura 3B). Pode ainda observar-se que as células que constituem a camada mais interna da cavidade são salientes no sentido do lume da cavidade. Essas células devem ser as responsáveis pela secreção dos óleos essenciais para o interior da cavidade.

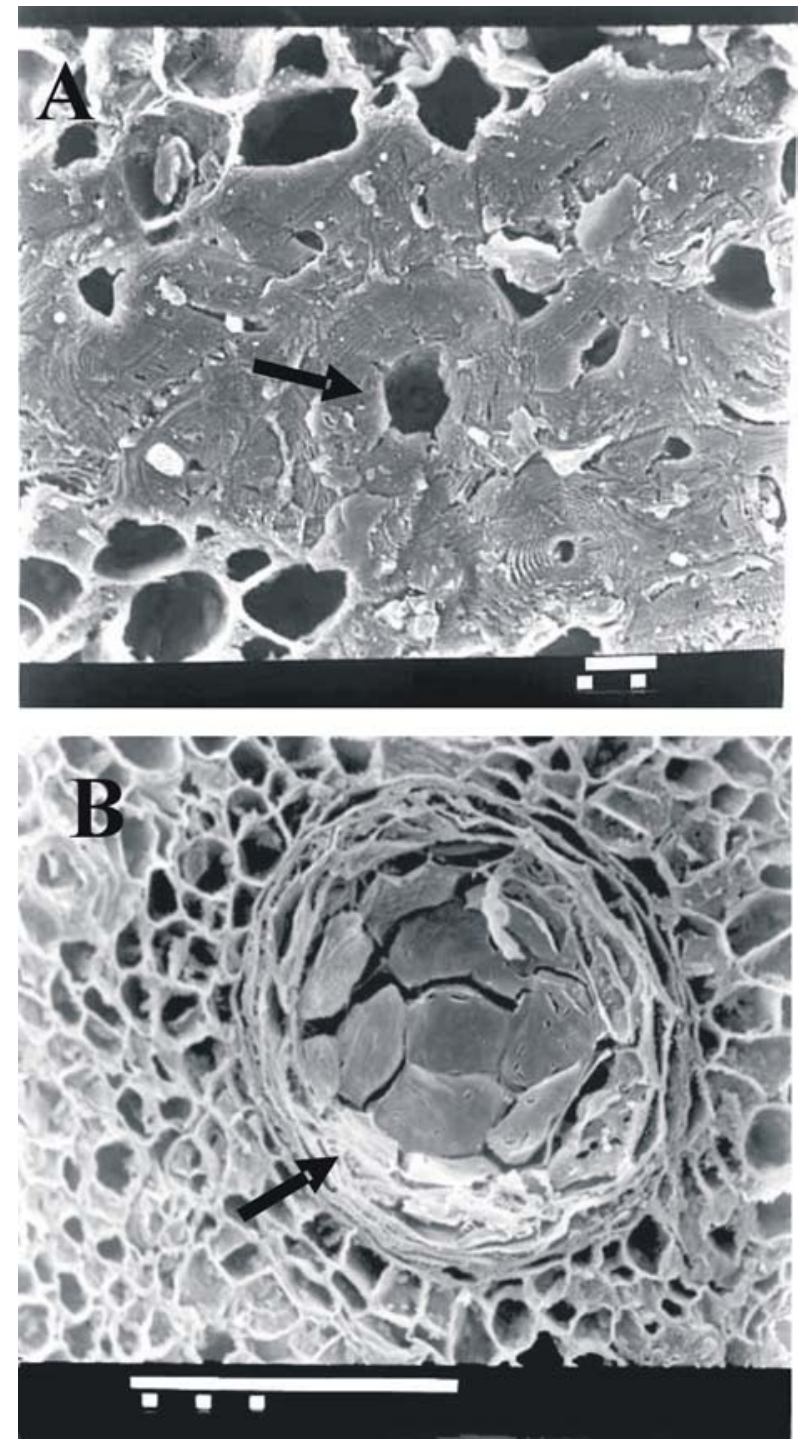

FIGURA 3- Estruturas de esclereídeos $(\rightarrow)($ barra $=10 \mu \mathrm{m})(\mathrm{A})$ e da cavidade lisígena $(\rightarrow)($ barra $=100 \mu \mathrm{m})(\mathrm{B})$, presente na face interna do pericarpo do fruto de Psidium guajava.

\section{CONCLUSÕES}

As características observadas, como a presença de cutícula espessa, cera epicuticular, três camadas subepidérmicas de células compactas e grande quantidade de esclereídeos, bem como a presença esporádica e dispersa de estômatos, poderiam constituir-se em barreiras para a absorção e movimentação de nutrientes e substâncias nos frutos de goiabeira.

\section{REFERÊNCIAS BIBLIOGRÁFICAS}

BLANKE, M.M. Stomata of currant fruits. Angewandte Botanik, v.67,n.12,p.1-2,1993.

BLANKE, M.M.; LOVATT, C.J. Anatomy and transpiration of the avocado inflorescence. Annals of Botany London, v.71, n.6,p.543-
$547,1993$.

CARVALHO, H.A.; CHITARRA, MI.F.; CHITARRA, A.B.; MENEZES, J.B. Eficiência da concentração de cloreto de cálcio e do tempo de imersão no tratamento pós-colheita de goiaba de polpa branca cv. Kumagai. Revista Brasileira de Fruticultura,v.20,n.3,p.375-381,1998.

CASTELLANE, P.D. Podridão apical em frutos de tomateiro. Jaboticabal, FUNEP, 1988.39p.

CHEOUR, F.; WILLWMOT, C.;ARUL, J.; MAKHLOUF, J.; DESJARDINS, Y. Postharvest response of two Strawberry cultivars to foliar application of $\mathrm{CaCl}_{2}$. HortScience, v.26,n.91,p.1186-1188,1991.

DANIELE, R.; GIRARDI, C.L.; PARUSSOLO,A.;FERRI, V.C.; ROMBALDI, C.V. Efeito da aplicação de ácido giberélico e cloreto de cálcio no retardamento da colheita e na conservalibilidade de caqui, Fuyu. Revista Brasileira de Fruticultura, v.24,n.1,p.44-48,2002.

FÁVERO, J.S.A. Crescimento e produção de Coffea arabica L. em resposta à nutrição foliar de zinco na presença de cloreto de potássio. Viçosa, 1992. 91p. Dissertação (Mestrado) - Universidade Federal de Viçosa.

KARCZ, J. Fruit micromorphology and anatomy of Valeriana officinalis s. str. (Valerianaceae). Nordic Journal of Botany, v.16,n.4,p.409419,1996.

KURZWEIL, H., LINDER, H.P., STERN, W.L. \& PRIDGEON, A.M. Comparative vegetative anatomy and classification of Diseae (Orchidaceae). Botanical Journal of the Linnean Society,v.117,p.171220,1995.

LANDRIGAN, M.; SARAFIS, V.; MORRIS, S.C.; MAGLASSON, W.B. Structural aspects of rambutan (Nephelium Lappaceum) fruits and their relation to postharvest browning. Journal of Horticultural Science, v.69,n.3,p.571-579,1994.

LURIE, S.; KLEIN, J.D. Calcium and heat treatment to improve storability of "Anna" apples. HortScience, v.27,n.1,p.36-39,1992.

MALTA, M.R. Absorção, transporte, compartimentalização e metabolismo do zinco aplicado via foliar em mudas de cafeeiro (Coffea arabica L.). Lavras, 2000. 57p. Dissertação (Mestrado) - Universidade Federal de Lavras.

MÔRO, F.V.; NATALE, W.; DAMIÃO FILHO, C.F. Relationships between leaf morphology and efficiency of foliar application of nutrients in guava (Psidium guajava L.). Acta Microscopica, v.8,n.2,p. 39-42, 1999.

MOTA, W.F.; SALOMÃO, L.C.C.; PEREIRA, M.C.T; VIEIRA, G.; FINGER, F.L. Influência do tratamento pós-colheita com cálcio na conservação de jabuticabas. In: CONGRESSO BRASILEIRO DE FISIOLOGIA VEGETAL, 6., Belém, 1997. Resumos... Belém: SBFV,1997.p.247.

NATALE, W.; BOARETTO, A.E.; MURAOKA, T. Absorption et redistribution de ${ }^{32} \mathrm{P}$ appliqué sur feuille de goyavier. Fruits, v.54,n.1,p.23-29, 1999.

RABELO, J.E.S.; SILVA, M.M.; GASPAR, J.W.; COUTO, F.A.A. Efeito da aplicação foliar de cloreto de cálcio e ácido bórico sobre o "colapso interno" da manga "Tommy Atkins". In: SÃO JOSÉ, A.R.; SOUZA, I.V.B.; MARTINS FILHO, J.; MORAIS, O.M. (Coord.) Manga: tecnologia de produção e mercado. Vitória da Conquista: DFZ/ UESB, 1996. p.136-138.

ROSSO, S.W. The vegetative anatomy of the Cypripedioideae (Orchidaceae). Journal of the Linnean Society Botany. v.59,p.309341,1996.

SILVA, A.P.; VIEITES, R.L. Tratamento pós-colheita com cloreto de cálcio aplicado por infiltração, nas características físicas do maracujazeiro. Revista Brasileira de Fruticultura, v.22,n.especial,p.73-76,2000.

SILVA, A.V.C.; MENEZES, J.B. Qualidade de manga "Tommy Atkis"submetida à aplicação pré-colheita de cloreto de cálcio. Revista Brasileira de Fruticultura,v.22,n.especial,p.86-90,2000.

TOZELLO, L.J.; RIBEIRO, W.R.C. Tratamento pós-colheita de goiaba (Psidium guajava L.) contra podridão de Guignardia psidii. Revista Brasileira de Fruticultura,v.20,n.2,p.229-234,1998.

WITHNER, C.L.; NELSON, P.K. \& WEJKSNORA, P.J. The anatomy of orchids. In: The Orchids: scientific studies (C.L. Withner, ed.). John Wiley, New York, p.267-334,1974. 